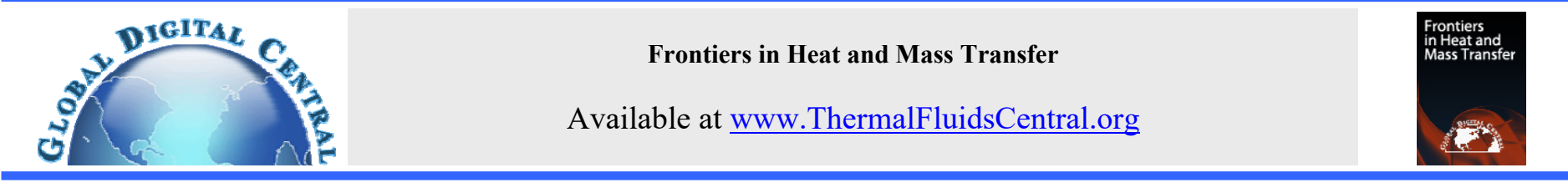

\title{
BIO-MATHEMATICAL ANALYSIS FOR THE STAGNATION POINT FLOW OVER A NON-LINEAR STRETCHING SURFACE WITH THE SECOND ORDER VELOCITY SLIP AND TITANIUM ALLOY NANOPARTICLE
}

\author{
S.R.R. Reddy ${ }^{\mathrm{a}}$, P. Bala Anki Reddy ${ }^{\mathrm{a}, *}$ \\ a Department of Mathematics, School of Advanced Sciences, VIT University, Vellore-632014, INDIA.
}

\begin{abstract}
The main object of this paper is to steady the Bio-mathematical analysis for the stagnation point flow over a non-linear stretching sheet with the velocity slip and Casson fluid model. Analysis for the both titanium and titanium alloy within the pure blood as taken as the base fluid. The governing non-linear partial differential equations are transformed into ordinary which are solved numerically by utilizing the fourth order RungeKutta method with shooting technique. Graphical results have been presented for dimensionless stream function, velocity profile, shear stress, temperature profile for various physical parameters of interest. It was found that the velocity profile of the nanofluids decreases and increases with the increasing the first-order and second-order slips respectively. Comparisons with previously published work are performed and the results are found to be excellent agreement.
\end{abstract}

Keywords: Stagnation point flow; velocity slip model; Casson fluid; viscous dissipation; non-linear stretching sheet; nanofluid.

\section{INTRODUCTION}

A study of boundary layer behavior over a stretching sheet problems has attracted the attention of its extensive industrial applications, such as aerodynamic extrusion of plastic sheets, extrusion of a polymer sheet from a dye, condensation process of metallic plates in cooling baths and some engineering applications, such as paper production, metal spinning, manufacture of foods, aerodynamic extrusion of plastic and rubber sheets etc. The viscous flow over a nonlinearly stretching sheet was developed by Vajravelu (2001). Elbashbeshy (1998) demonstrated heat transfer over a stretching surface with variable surface heat flux. Thirupathi et al. (2017) numerically investigated the heat source/sink effects on dissipative magnetic nanofluid flow from a non-linear inclined stretching/shrinking sheet. Bhatti et al. (2018) examined the irrotational flow of an MHD viscous fluid over a permeable shrinking sheet. Seth et al. (2018) proposed the 2D viscoelastic fluid past over a stretching surface. Many researchers (Idrees et al. 2018; Hamad and Ferdown, 2012; Mahapatra and Gupta, 2002; Ali, 1994; Bala Anki Reddy and Vijaya Sekhar, 2013; Cortell, 2007; Srinivas et al., 2014; Rana and Bhargava, 2017; Pop et al., 2004; Sharma and Singh, 2009; Thumma et al. 2017) investigated the different flow problems over a stretching sheet. In the past, there has been a number of studies to examine the heat transfer in blood vessels. Charm et al. (1968) experimentally investigated heat transfer in small tubes of diameter 0.6, in a water bath. Victor and shah (1975) computed the heat transfer for uniform heat flux and uniform wall temperature cases for fully developed flow and in the entrance region. Li and Huang (1976) explored the effect of steady spatially varying magnetic field on blood flow and heat transfer through a stenosed artery. In their research, blood is considered as a non-Newtonian fluid and the model concerns the effect of varying viscosity and electrical conductivity on blood flow.
The steady of non-Newtonian fluids has a verity of applications in engineering and industry especially in extraction of crude oil form petroleum procedures as well as biological fluids such as lubricating greases, multi-grade oils, printer inks, paints, gypsum pastes, ceramics, liquid detergents, blood, fruit juices etc. Casson fluid models are a preferred rheological model for many fluids including blood and chocolate, the behavior of these models exhibits a yield stress. Some researchers examined the flow and heat transfer analysis of Casson fluid can be found in Refs. (Li and Huang, 2010; Gireesha et al., 2015; Dash et al., 1996; Nadeem et al., 2012; Bala Anki Reddy, 2016; Nadeem et al., 2013; Thumma et al. 2018). 3D Casson fluid flow past a porous linearly stretching sheet with convective boundary condition was analyzed by Mahanta and Shaw (2015). Mustafa et al. (2011) proposed the temperamental limit layer stream of a Casson liquid due to an indiscreetly began moving level plate. MHD stream of a Casson liquid over an exponentially contracting sheet was researched by Nadeem et al. (2012).

Nano particle examination is in the blink of an eye a region of effective experimental enthusiasm because of a gigantic scope of potential applications in electronic, biomedical and optical fields. Nanofluid is define as the combination of the base fluid with nanoparticles that have unique physical and chemical properties. It is used to enhance the rate of heat transfer of microchips in computers, microelectronics, transportation, biomedicine, food processing, fuel cells, solid state lightening and manufacturing. The nanoparticles are mostly found in the metals such as nitrides, non-metals or carbides (carbon nanotubes, Graphite). The word nanofluid was firstly introduced by choi (1995). Mustafa et al. (2011) examined the stagnation-point flow of a nanofluid towards a stretching sheet. The Cheng-Minkowycz problem for natural convective boundary-layer flow over a porous medium saturated by a nanofluid was discussed by Nield and Kuznetsov (2009). Hayat (2016) studied the Homogeneous-

*Corresponding author. Email: pbarmaths@gmail.com 
heterogeneous reactions in the stagnation point flow of carbon nanotubes with Newtonian heating.

The motivation behind the present examination is to inspect the significance of nanofluid over a non-linear stretching sheet with the velocity slip (the first-order and second-order velocity slips) using the Ti and Ti-alloy nanoparticles on blood (as the base fluid).

\section{MATHEMATICAL FORMULATION}

Consider two-dimensional stagnation point flow of nanofluid by an impermeable nonlinear stretching or shrinking sheet. The sheet is stretched with non-linear velocity $u_{w}(x)=c x^{m}$, where $c$ is a constant for which $c>0$ corresponds to the stretching sheet and $c<0$ for shrinking sheet and $m$ is a power index and wall mass suction velocity is $v=v_{w}(x)$ with $v_{w}<0$ for suction and $v_{w}>0$ for injection respectively. The pressure gradient and external forces are neglected. By keeping the origin is fixed and the $x$-axis is taken along the stretching sheet in the direction of the motion and the $y$-axis is perpendicular to the sheet in the outward direction towards the fluid of ambient temperature $T_{\infty}$ as $y \rightarrow \infty$. A non-uniform transverse magnetic field of strength $B(\mathrm{x})=\mathrm{B}_{0} x^{(\mathrm{m}-1) / 2}$ is applied in the transverse direction, where $B_{0}$ is the constant related to magnetic field and $m(\neq-1)$ is a power law exponent. The thermophysical properties of the nanofluids are given in Table 1. The rheological equation for incompressible flow of a Casson fluid is given by

$\tau_{i j}=\left\{\begin{array}{l}2\left(\mu_{B}+p_{y} / \sqrt{2 \pi}\right) e_{i j}, \pi>\pi_{c} \\ 2\left(\mu_{B}+p_{y} / \sqrt{2 \pi_{c}}\right) e_{i j}, \pi<\pi_{c}\end{array}\right.$

Here $\pi=e_{i j} e_{i j}$ and $e_{i j}$ are the $(i, j)^{t h}$ component of the deformation rate, $\mu_{B}$ is the plastic dynamic viscosity of the non-Newtonian fluid, $p_{y}$ is the yield stress of the fluid, $\pi$ is the product of the component of deformation rate with itself and $\pi_{c}$ is a critical value of this product based on the non-Newtonian model.

\subsection{Flow analysis}

The governing equations of the flow are given by

$\frac{\partial u}{\partial x}+\frac{\partial v}{\partial y}=0$

$u \frac{\partial u}{\partial x}+v \frac{\partial u}{\partial y}=u_{e} \frac{d u_{e}}{d x}+v_{n f}\left(1+\frac{1}{\beta}\right) \frac{\partial^{2} u}{\partial y^{2}}$

$$
+\frac{(\rho \beta)_{n f}}{\rho_{n f}} g\left(T-T_{\infty}\right) \cos \alpha+\frac{\sigma B^{2}(\mathrm{x})}{\rho_{n f}}\left(u_{e}-u\right)
$$

With the boundary conditions

$$
u=c x^{m}+\mathrm{U}_{\text {slip }}, v=v_{w} \text {, at } y=0, u \rightarrow u_{e}(x)=c_{\infty} x^{m} \text { at } y \rightarrow \infty \text {, }
$$

Where (x,y) denotes the Cartesian coordinates along the sheet. $u$ and $v$ are the velocity components of the nanofluid along the $x$ and $y$ axes respectively, $v_{n f}$ is the kinematic viscosity of nanofluid, $\rho_{n f}$ is the effective density of the nanofluid, $\beta$ is the Casson fluid parameter $\left(\beta=\mu_{B} \sqrt{2 \pi} / p_{y}\right),\left(\rho c_{p}\right)_{n f}$ is the heat capacitance of the nanofluid, $u_{e}$ is the free stream velocity, $\sigma$ is the effective electrical conductivity. These nanofluid quantities are defined as

$$
\begin{aligned}
& \mu_{n f}=\frac{\mu_{f}}{(1-\phi)^{2.5}}, v_{n f}=\frac{\mu_{n f}}{\rho_{n f}}, \rho_{n f}=(1-\phi) \rho_{f}+\phi \rho_{s}, \\
& \frac{\sigma_{n f}}{\sigma_{f}}=\left(1+\frac{3(\sigma-1) \phi}{(\sigma+2)-(\sigma-1) \phi}\right), \sigma=\frac{\sigma_{s}}{\sigma_{f}},
\end{aligned}
$$

$$
\alpha_{n f}=\frac{k_{n f}}{\left(\rho C_{p}\right)_{n f}}, \frac{k_{n f}}{k_{f}}=\frac{(1-\phi)+2 \phi \frac{k_{s}}{k_{s}-k_{f}} \ln \frac{k_{s}+k_{f}}{2 k_{f}}}{(1-\phi)+2 \phi \frac{k_{f}}{k_{s}-k_{f}} \ln \frac{k_{s}+k_{f}}{2 k_{f}}}
$$

where $\phi$ is the solid volume fraction, $\mu_{n f}$ is the effective dynamic viscosity, $\rho_{n f}$ is the effective density, $k_{n f}$ is the thermal conductivity of nanofluid, $\mu_{f}$ is the dynamic viscosity, $\rho_{f}$ and $\rho_{s}$ are the densities, $k_{f}$ and $k_{s}$ are the thermal conductivities. It should be noted that ()$_{f}$ and ()$_{s}$ denotes the basic fluid and nanoparticles respectively.

$\mathrm{U}_{\text {slip }}$ is consider in the form (Wu [39])

$$
\begin{aligned}
U_{s l i p} & =\frac{2}{3}\left(\frac{3-\alpha_{m} l^{3}}{\alpha_{m}}-\frac{3}{2} \frac{1-l^{2}}{K_{n}}\right) \lambda_{m} \frac{\partial u}{\partial y}-\frac{1}{4}\left[l^{4}+\frac{2}{K_{n}^{2}}\left(1-l^{2}\right)\right] \lambda_{m}^{2} \frac{\partial^{2} u}{\partial y^{2}} \\
\mathrm{U}_{\text {slip }} & =A^{*} \frac{\partial u}{\partial y}+C^{*} \frac{\partial^{2} u}{\partial y^{2}}
\end{aligned}
$$

Where $\lambda_{m}$ is the molecular mean free path, $\alpha_{m}$ is the momentum accommodation coefficient with $0 \leq \alpha_{m} \leq 1, K_{n}$ is the Knudsen number and $l=\min \left(\frac{1}{K_{n}}, 1\right)$. Based on the definition of $l$, it is noticed that for any given value of $K_{n}$, we have $0 \leq l \leq 1$. The mean free path of molecular is always positive it results that $C^{*}$ is a negative number.

To convert the nonlinear partial differential equations into ordinary nonlinear differential equations, we introduce the self-similarity variables in the following form are given by

$\eta=\left(\frac{(m+1) u_{w}(x)}{2 v_{f} x}\right)^{1 / 2} y, \psi=\left(\frac{2 v_{f} x u_{w}(x)}{m+1}\right)^{1 / 2} f(\eta), \theta(\eta)=\frac{T-T_{\infty}}{T_{w}-T_{\infty}}$

Where $\eta$ is the similarity variable, $f(\eta)$ is the dimension less stream function, $\theta(\eta)$ is the dimensionless temperature. $\psi$ is the stream function which is defined by $u=\partial \psi / \partial y$ and $v=-\partial \psi / \partial x$. The above expression also satisfies the continuity Eq. (1). By using Eqs. (4) -(6), the Eq. (2) reduced to:

$$
\begin{aligned}
& \left(\frac{1}{(1-\phi)^{2.5}}\right)\left(1+\frac{1}{\beta}\right) f^{\prime \prime \prime}+\left(1-\phi+\phi \frac{\rho_{s}}{\rho_{f}}\right)\left(f f^{\prime \prime}-\frac{2 m}{m+1}\left(\left(f^{\prime}\right)^{2}-A^{2}\right)\right) \\
& +\frac{2}{m+1}\left((1-\phi)+\phi \frac{(\rho \beta)_{s}}{(\rho \beta)_{f}}\right)(R i \cos \alpha) \theta-M \frac{2}{m+1}\left(f^{\prime}-A\right)=0
\end{aligned}
$$

and the transformed boundary conditions are:

$f(0)=S, f^{\prime}(0)=1+\lambda f^{\prime \prime}(0)+\delta f^{\prime \prime \prime}(0), f^{\prime}(\eta) \rightarrow A$ as $\eta \rightarrow \infty$

Where $\lambda>0$ and $\delta<0$ are the first order and second order velocity slips, respectively, $\mathrm{M}=\sigma B_{0}^{2} / c \rho_{f}$ is the magnetic parameter, $R i=G r / \operatorname{Re}_{x}^{2}$ is the Richardson number, $G r=g \beta_{f}\left(T_{w}-T_{\infty}\right) x^{3} / v_{f}^{2}$ is the local Grashof number, $\operatorname{Re}_{x}=x u_{w} / v_{f}$ is the local Reynolds number based on the stretching/shrinking velocity $u_{w}, A=c_{\infty} / c$ is the ratio of free stream velocity $c_{\infty}$ to stretching/shrinking velocity $c$, $S=-v_{w} x^{-(m-1) / 2} \sqrt{2 / c(m+1) v_{f}} \quad(S>0$ corresponds to the suction and $S>0$ corresponds to blowing parameter).

\subsection{Heat transfer analysis}

The boundary layer energy equation is given by 


$$
\begin{aligned}
u \frac{\partial T}{\partial x}+ & v \frac{\partial T}{\partial y}=\alpha_{n f} \frac{\partial^{2} T}{\partial y^{2}}+\frac{1}{\left(\rho c_{p}\right)_{n f}} \frac{\partial q_{r}}{\partial y} \\
& +\frac{\mu_{n f}}{\left(\rho c_{p}\right)_{n f}}\left(1+\frac{1}{\beta}\right)\left(\frac{\partial u}{\partial y}\right)^{2}+\frac{Q_{0}}{\left(\rho c_{p}\right)_{n f}}\left(T-T_{\infty}\right)
\end{aligned}
$$

Thermal radiation is simulated using the Rosseland diffusion approximation and in accordance with this, the radiative heat flux $q_{r}$ is given by

$q_{r}=-\frac{4 \sigma^{*}}{3 k^{*}} \frac{\partial T^{4}}{\partial y}$

Where $k^{*}$ is the Rosseland mean absorption coefficient and $\sigma *$ is the Stefan-Boltzmann constant. If the temperature differences within the mass of blood flow are sufficiently small, then Eq. (10) can be linearized by expanding $T^{4}$ into the Taylor's series about $T_{\infty}$, and neglecting higher-order terms, we get

$T^{4} \cong 4 T_{\infty}^{3} T-3 T_{\infty}^{4}$

Therefore Eq. (9) becomes

$$
\begin{aligned}
u \frac{\partial T}{\partial x}+v \frac{\partial T}{\partial y}= & \alpha_{n f} \frac{\partial^{2} T}{\partial y^{2}}-\frac{16 \sigma^{*} T_{\infty}^{3}}{3 k^{*}\left(\rho C_{p}\right)_{n f}} \frac{\partial^{2} T}{\partial y^{2}} \\
& +\frac{\mu_{n f}}{\left(\rho c_{p}\right)_{n f}}\left(1+\frac{1}{\beta}\right)\left(\frac{\partial u}{\partial y}\right)^{2}+\frac{Q_{0}}{\left(\rho c_{p}\right)_{n f}}\left(T-T_{\infty}\right)
\end{aligned}
$$

With the corresponding boundary conditions

$T=T_{w}(x)=\mathrm{T}_{\infty}+c_{1} x^{n}$ at $y=0$ and $T \rightarrow T_{\infty}$ at $y \rightarrow \infty$

Where $T_{W}$ is the wall temperature.by using self-similarity transformations of Eqs. (4) and (6) the Eq. (12) reduced to:

$$
\begin{aligned}
& \left(\frac{1}{p r}\left(\frac{k_{n f}}{k_{f}}+\frac{4}{3} N r\right)\right) \theta^{\prime \prime}+\left(1-\phi+\phi \frac{\left(\rho c_{p}\right)_{C N T}}{\left(\rho c_{p}\right)_{f}}\right) \\
& \quad\left(f \theta^{\prime}-\frac{2 n}{m+1} f^{\prime} \theta\right)+\frac{E c}{(1-\phi)^{2.5}}\left(1+\frac{1}{\beta}\right) f^{\prime \prime 2}+\frac{2 Q}{m+1} \theta=0,
\end{aligned}
$$

and the transformed boundary conditions are:

$\theta(0)=1, \theta(\eta) \rightarrow 0$ as $\eta \rightarrow \infty$

Where $\operatorname{Pr}=v_{f} / \alpha_{f}$ is the Prandtl number and $N r=4 \sigma^{*} T_{\infty}^{3} / k^{*} k_{f}$ is the radiation conduction parameter, $E c=u_{w}^{2} /\left(T_{w}-T_{\infty}\right)\left(c_{p}\right)_{f}$ is the Eckert number, $Q=x Q_{0} / u_{w}\left(\rho c_{p}\right)_{f}$ is the heat source parameter. In this study, the quantities of practical interest are skin friction coefficient $C_{f}$ and local Nusselt number $N u$, which are defined as

$C_{f}=\frac{\tau_{w}}{\rho_{f} u_{w}^{2}}, N u_{x}=\frac{x q_{w}}{k_{f}\left(T_{w}-T_{\infty}\right)}$,

Where $\tau_{W}=\mu_{n f}\left(1+\frac{1}{\beta}\right)\left(\frac{\partial u}{\partial y}\right)_{y=0}, q_{w}=-k_{n f}\left(\frac{\partial T}{\partial y}\right)_{y=0}$

Dimensionless skin fraction coefficient and local Nusselt number are expressed as follows:

$$
\begin{aligned}
& C_{f} \operatorname{Re}_{x}^{1 / 2}=\frac{1}{(1-\phi)^{2.5}}\left(1+\frac{1}{\beta}\right) \sqrt{\frac{m+1}{2}} f^{\prime \prime}(0), \\
& N u_{x} \operatorname{Re}_{x}^{-1 / 2}=-\frac{K_{n f}}{K_{f}} \sqrt{\frac{m+1}{2}} \theta^{\prime}(0)
\end{aligned}
$$

\section{NUMERICAL PROCEDURE}

Equations (8) and (15) along with boundary conditions (9) and (16) form a two-point boundary value problem. These equations are solved using the fourth order Runge-Kutta method along with shooting technique, by converting them to an initial value problem. For this we transform the non-linear ordinary differential equations (8) and (15) to a system of first order differential equations as follows:

$$
\begin{aligned}
& f^{\prime}=z, z^{\prime}=p, \\
& \left(1-\phi+\phi \frac{\rho_{s}}{\rho_{f}}\right)=a 1,\left((1-\phi)+\phi \frac{(\rho \beta)_{s}}{(\rho \beta)_{f}}\right)=a 2 \\
& p^{\prime}=-\frac{(1-\phi)^{2.5}}{\left(1+\frac{1}{\beta}\right)}\left\{\begin{array}{l}
a 1\left(f p-\frac{2 m}{m+1}\left(z^{2}-A^{2}\right)\right)+ \\
\frac{2}{m+1} a 2(R i \cos \alpha) \theta-M \frac{2}{m+1}(z-A)
\end{array}\right\} \\
& \theta^{\prime}=q, \mathrm{a}=\left((1-\phi)+\phi \frac{\left(\rho C_{p}\right)_{C N T}}{\left(\rho C_{p}\right)_{f}}\right), b=\left(\frac{k_{n f}}{k_{f}}+\frac{4}{3} N r\right) \\
& q^{\prime}=-\frac{p r}{b}\left\{a\left(f q-\frac{2 n}{m+1} z \theta\right)+\frac{E c}{(1-\phi)^{2.5}}\left(1+\frac{1}{\beta}\right) p^{2}+\frac{2 Q}{m+1} \theta\right\}
\end{aligned}
$$

The boundary conditions (9) and (16) becomes

$$
\begin{aligned}
& f(0)=S, f^{\prime}(0)=1+\lambda \omega_{1}+\delta \omega_{2}, \\
& \omega_{1}=f^{\prime \prime}(0), \omega_{2}=f^{\prime \prime \prime}(0), \theta(0)=1
\end{aligned}
$$

In order to integrate (20) $-(21)$ as initial value problem, we require values of $p(0)$ i.e., $f^{\prime \prime}(0), q(0)$ i.e., $\theta^{\prime}(0)$. But no such values are given at the boundary. So the suitable guess values for $f^{\prime \prime}(0)$ and $\theta^{\prime}(0)$ are chosen and then integration is carried out. The most important factor of this package is to choose an appropriate finite value of $\eta_{\infty}$. In order to determine $\eta_{\infty}$ for the boundary value problem, start with some initial guess values for some particular set of physical parameters to obtain $f^{\prime \prime}(0)$ and $\theta^{\prime}(0)$. The solving procedure is repeated with another value of $\eta_{\infty}$ until two successive values of $f^{\prime \prime}(0)$ and $\theta^{\prime}(0)$ differ only by the specified significant digit. The last value of $\eta_{\infty}$ is finally chosen to be the most appropriate value of the $\eta_{\infty}$ for that particular set of parameters. The value of $\eta_{\infty}$ may change for another set of physical parameters. Once the finite value of $\eta_{\infty}$ is determined, then the integration is carried out. Compare the calculated values for $f^{\text {' }}$ and $\theta$ at $\eta=30$ (say) with the boundary conditions $f^{\prime \prime}(30=0)$ and $\theta^{\prime}(30)=0$ and adjust the estimated values, $f^{\prime \prime}(0)$ and $\theta^{\prime}(0)$ to give better approximation to the solution. We take the series values for $f^{\prime \prime}(0)$ and $\theta^{\prime}(0)$. The above procedure is repeated until to get the results up to desired degree of accuracy $10^{-6}$.

\section{RESULTS AND DISCUSSIONS}

The present section, we examine the stagnation point flow over a non-linear stretching sheet with the velocity slip and Casson fluid model. Numerical solution for dimensionless stream function, velocity profile, shear stress, temperature, local skin friction coefficient and local Nusselt number profile is obtained. Based on this numerical solution, we deliberate the possessions of numerous physical parameters such as magnetic parameter $(M)$, Richardson number $(R i)$, ratio parameter $(A)$, mass suction/blowing parameter $(S)$, the first order velocity slip $(\lambda)$, second order velocity slip $(\delta)$, volume fraction parameter $(\phi)$, Casson fluid parameter $(\beta)$, radiation conduction parameter $(\mathrm{Nr})$, Eckert number $(E c)$ and the heat source parameter $(Q)$ on the dimensionless stream function $(f(\eta))$, velocity profile $\left(f^{\prime}(\eta)\right)$, shear stress $\left(f^{\prime \prime}(\eta)\right)$, temperature $(\theta(\eta))$, local skin friction coefficient and local Nusselt number profiles. For numerical results, we considered 


$$
\begin{aligned}
M & =1.5, R i=0.2, \alpha=\pi / 4, S=0.1, A=0.8, p r=21, \phi=0.15, \\
\delta & =-0.1, N r=0.5, E c=0.1, Q=0.5, \mathrm{~m}=1.25, \mathrm{n}=2.5 .
\end{aligned}
$$

These values are conserved as common unless specifically pointed out in the appropriate graphs.

Figs. 1-4 depict the dimensionless stream function, velocity profile, shear stress, temperature profiles for various values of ratio parameter (A). $f(\eta)$ increase with the increase of ratio parameter. Whereas the reverse trend is observed in $\theta(\eta)$. Here we noticed that velocity profile and boundary layer thickness increase with an increase in ratio parameter $(A>1)$ and for $A<1$ the boundary layer thickness has in opposite effects. It is also noticed that is fluid and sheet move with the same velocity at $A=1$. At $A=0.8$ and 0.9 the nanofluid flow is decreasingly negative for shear stress with greater ratio. The effect of magnetic parameter on the dimensionless stream function, velocity profile, shear stress, temperature profiles of the nanoparticles $(\mathrm{Ti}, \mathrm{Ti}$ alloy) are illustrated in Figs. 5-8. It is observed that increase of $f(\eta), f^{\prime}(\eta)$ and $\theta(\eta)$ decrease uniformly over the entire domain for both nanofluids. Whereas the reverse trend is observed in $f^{\prime \prime}(\eta)$. Due to behind that Lorentz magnetohydrodynamic drag force which acts perpendicular to the magnetic field. For the large values of magnetic parameter, the graph of $f(\eta)$ and $f^{\prime}(\eta)$ reaches very rapidly to the $\eta_{\infty}$ and $\eta_{0}$, respectively.

Figs. 9-12 illustrate the dimensionless stream function, velocity profile, shear stress, temperature profiles for various values of first order velocity slip $(\lambda)$. From these figures, we noticed that $f(\eta), f^{\prime}(\eta)$ and $\theta(\eta)$ increase with increase the first order velocity slip and opposite phenomena is observed in $f^{\prime \prime}(\eta)$. The combined effects of Casson fluid parameter on the dimensionless stream function, velocity profile, shear stress, temperature profiles are displayed in Figs. 1316. $f(\eta), f^{\prime}(\eta), \theta(\eta)$ decrease and $f^{\prime \prime}(\eta)$ increase with increasing the Casson fluid parameter. Physically it makes sense because plasticity of fluid is higher as Casson fluid parameter goes higher and fluid experiences a resistance and also blood is non-Newtonian fluid.

The influence of Richardson number on the dimensionless stream function, velocity profile, shear stress, temperature profiles for both nano fluids cases are shown in Figs. 17-20. At the Richardson number $R i>0, R i<0$ and $R i=0$ represents the heating, cooling and absence of free convection currents respectively. $f(\eta)$ and $f^{\prime}(\eta)$ decreases with increase the Richardson number and opposite phenomena is observed for $f^{\prime \prime}(\eta)$. and $\theta(\eta)$. Here we observed that Ti-alloy-pure blood nanofluid is highly influenced when compared with Ti-pure blood.

Figs. 21-24 depict the dimensionless stream function, velocity profile, shear stress, temperature profiles for various values of suction/blowing parameter for both nano fluids cases. From these figures, it is seen that $f(\eta)$ increase with increase the suction/blowing parameter. An increasing in the suction/blowing parameter the velocity increases with in the interval $0 \leq \eta \leq 0.4$ after that a slight decrease in velocity have been observed. Whereas the reverse trend is observed in shear stress. An increase of suction/blowing parameter leads to declines the temperature profile. For the large values of suction/blowing parameter, the graph of $f^{\prime \prime}(\eta)$ and $f^{\prime}(\eta)$ reaches very rapidly to the $\eta_{0}$. The effect of second order velocity slip on the dimensionless velocity profile and shear stress parameter of the nanoparticles ( $\mathrm{Ti}, \mathrm{Ti}$ alloy) are illustrated in Figs. 25-26. It is concluded that the velocity and thermal boundary layer thickness are higher for large values of second order velocity slip parameter for both nanoparticles. $f^{\prime \prime}(\eta)$ decrease for higher values of second order slip parameter.

Fig. 27. Shows the variation of heat source parameter on temperature profile. An increase of heat source parameter leads to enhance the temperature profile due to the energized the nanofluids. The effect of radiation parameter on temperature is displayed in Fig. 28. It is noticed that the enhance temperature with higher values of radiation parameter.
Fig. 29 Illustrate the influence of Eckert number on temperature profile. As Eckert number increases enhances the wall temperature due to heat addition by frictional heating. Due to internal friction heating between molecules of the fluid, mechanical energy is converted to thermal energy which heats the fluid in sheet. The temperature is lower when $E c$ $=0$ because the term of viscous dissipation can be ignored in the expression of energy.

In order to investigate the impact of emerging parameters namely magnetic parameter, Casson fluid parameter, suction parameter $(S>0)$, first order velocity slip parameter, ratio parameter, radiation conduction parameter, heat source parameter on the local skin friction coefficient and local Nusselt number, graphical results are constructed in figs 30 32. Fig. 30 shows the behavior of Casson fluid, first order velocity slip, suction, and ratio parameter on local skin friction coefficient. Higher values of suction parameter result in the enhancement of local skin friction coefficient while it decreases for large values of ratio parameter. Whereas the reverse trend is observed in Casson fluid and first order velocity slip parameters. The effect of magnetic, Casson and ratio parameters on the local skin friction coefficient has been plotted in Fig. 31. When the nanoparticle volume fraction is in the range of $0 \leq \phi \leq 0.2$. It is found that an increase in the Casson fluid parameter and ratio parameter leads to increasing effect of absolute local skin friction coefficient. Whereas the reverse trend is observed in magnetic parameter.

Fig. 32 depicts the variation of local Nusselt number for various values of radiation conduction parameter and the heat source parameter. The local Nusselt number decrease with increase of radiation conduction parameter and the heat source parameter. The rate of heat transfer is higher in Ti-alloy-pure blood nanofluid when compared with the Ti-pure blood nanofluid.

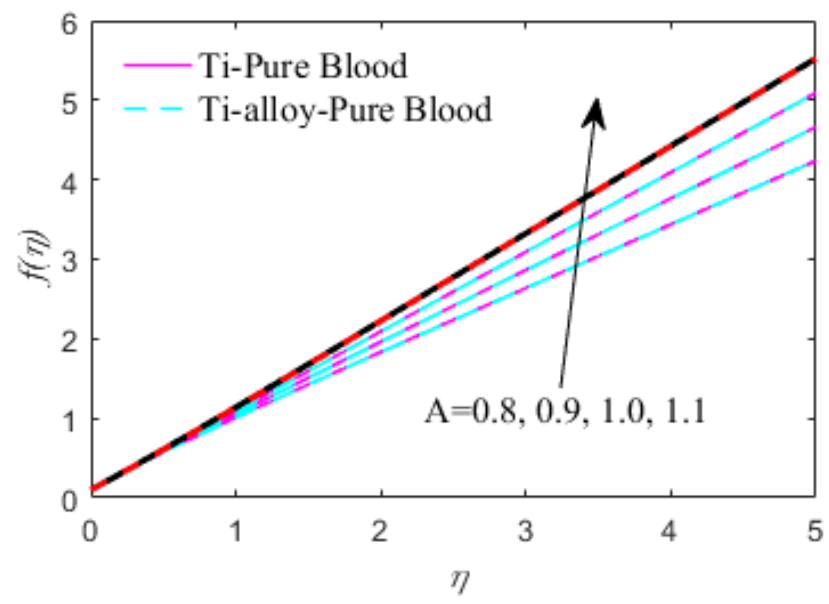

Fig. 1 Effect of $A$ on dimensionless stream function

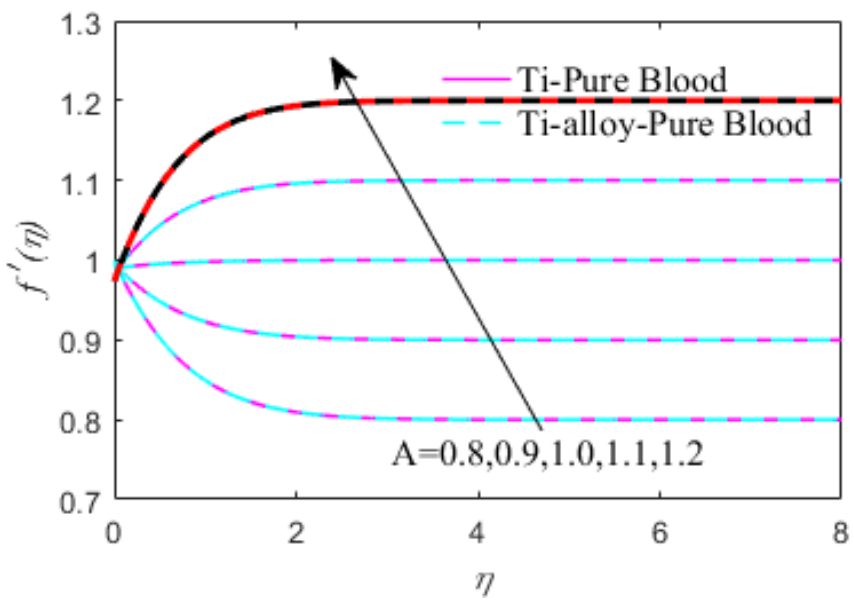

Fig. 2 Effect of $A$ on velocity profile 


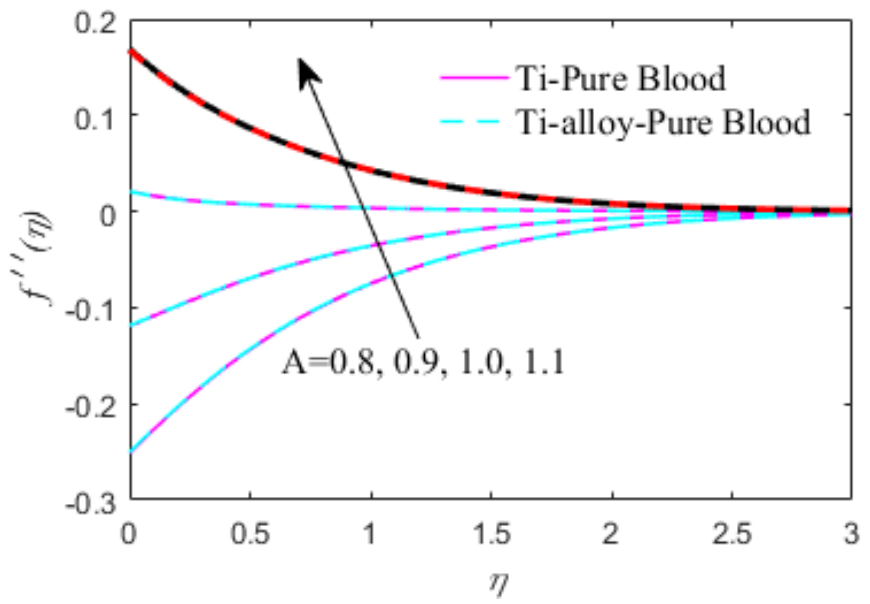

Fig. 3 Effect of $A$ on shear stress

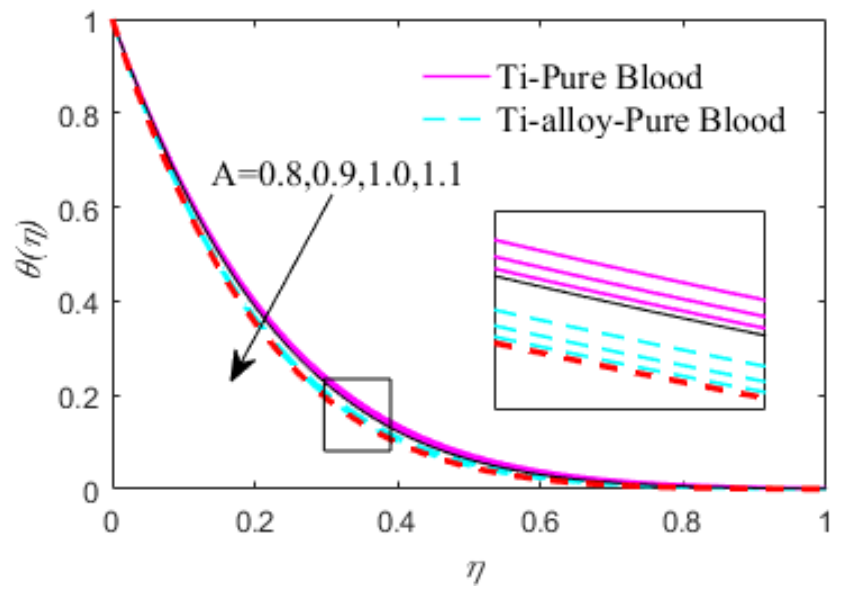

Fig. 4 Effect of $A$ on temperature profile

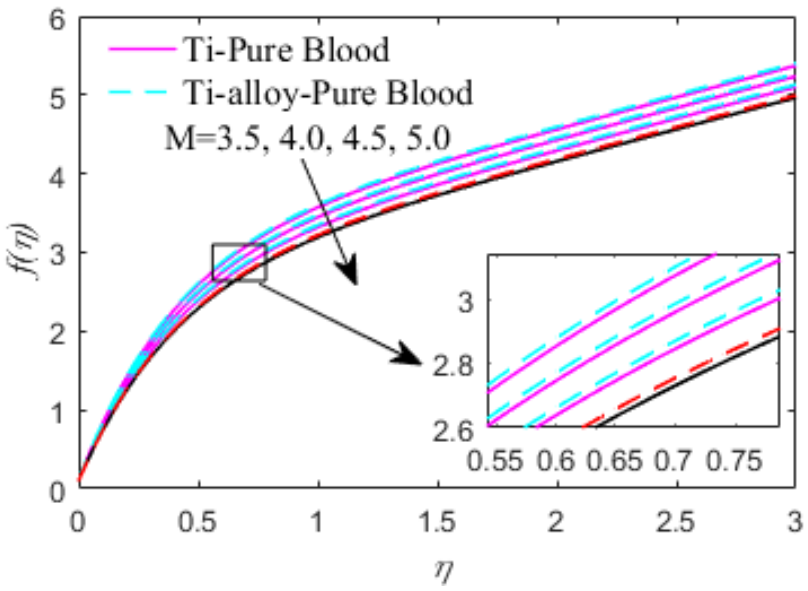

Fig. 5 Effect of $M$ on dimensionless stream function

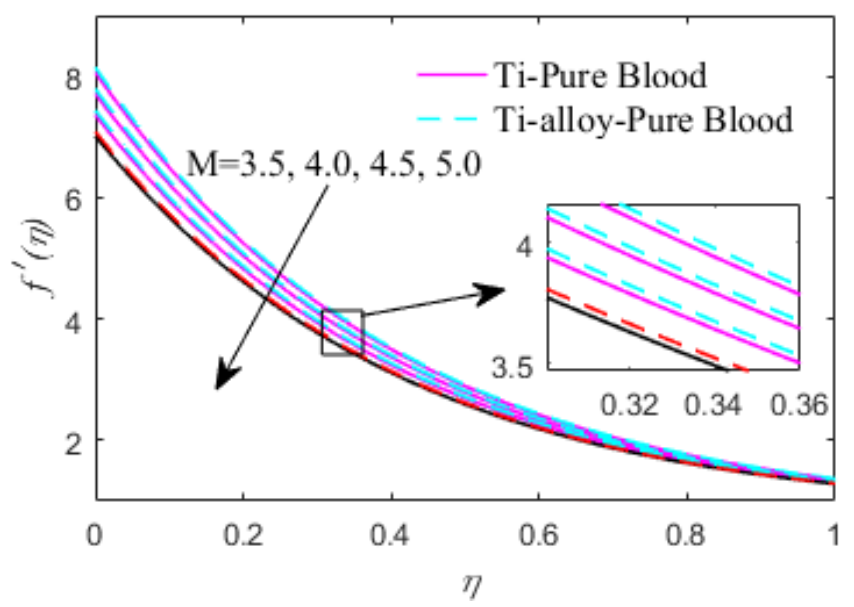

Fig. 6 Effect of $M$ on velocity profile

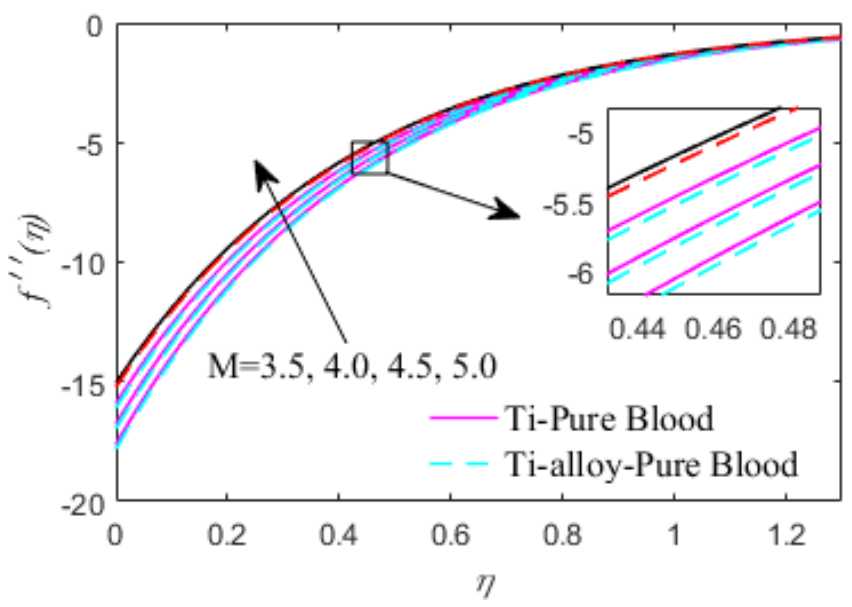

Fig. 7 Effect of $M$ on shear stress

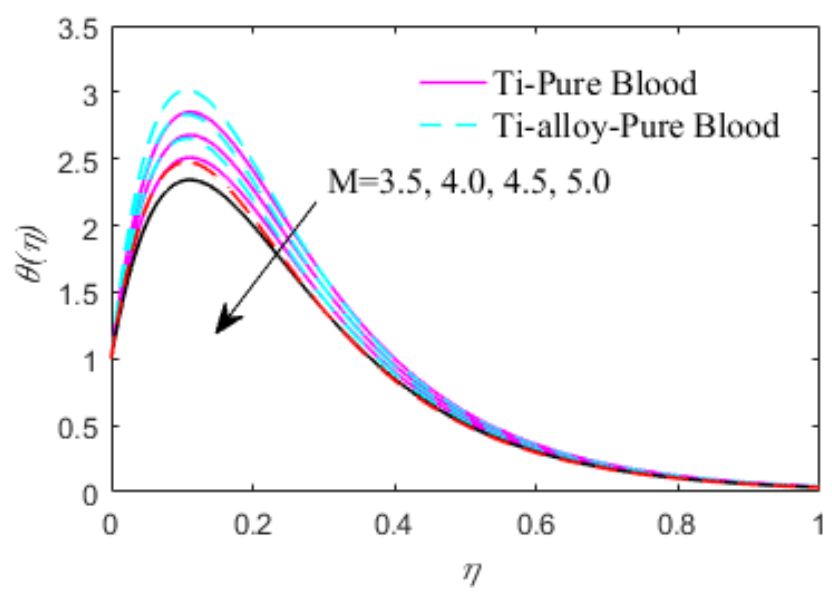

Fig. 8 Effect of $M$ on temperature profile 


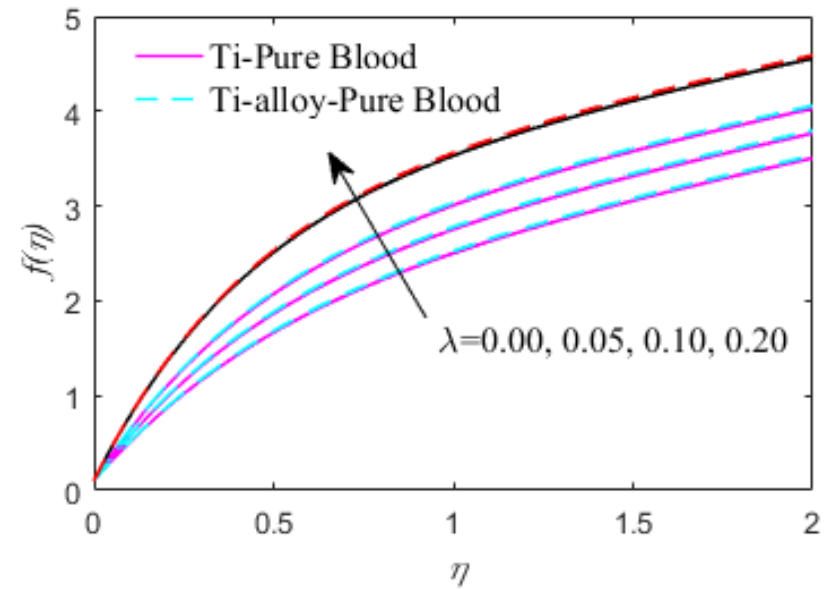

Fig. 9 Effect of $\lambda$ on dimensionless stream function

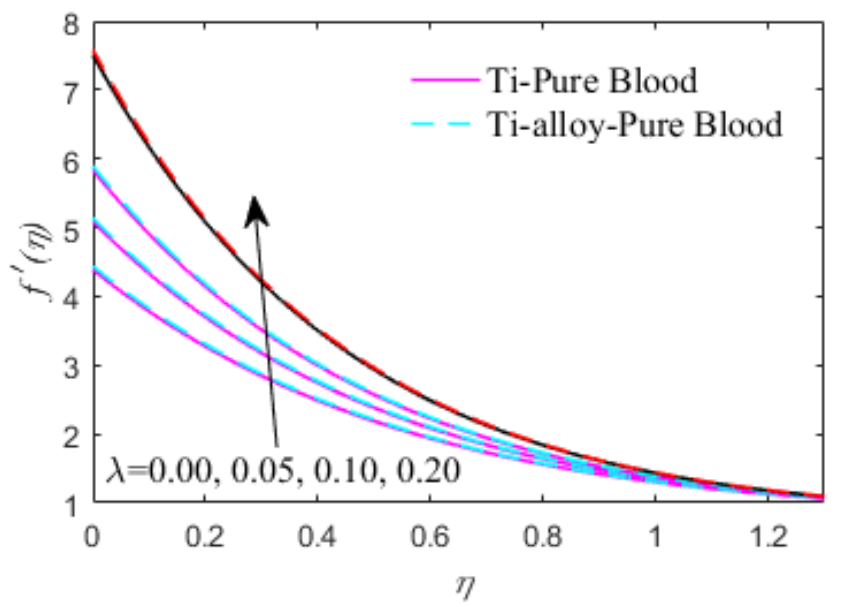

Fig. 10 Effect of $\lambda$ on velocity profile

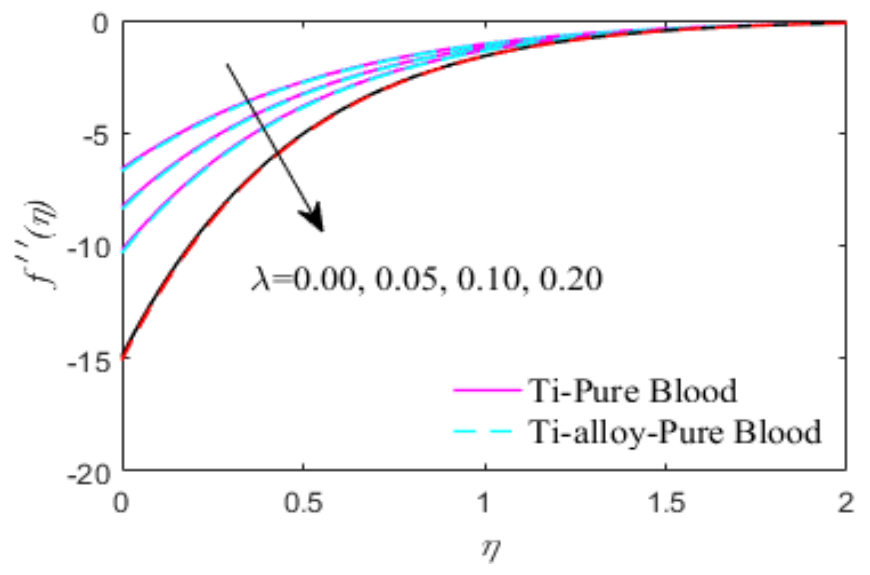

Fig. 11 Effect of $\lambda$ on shear stress

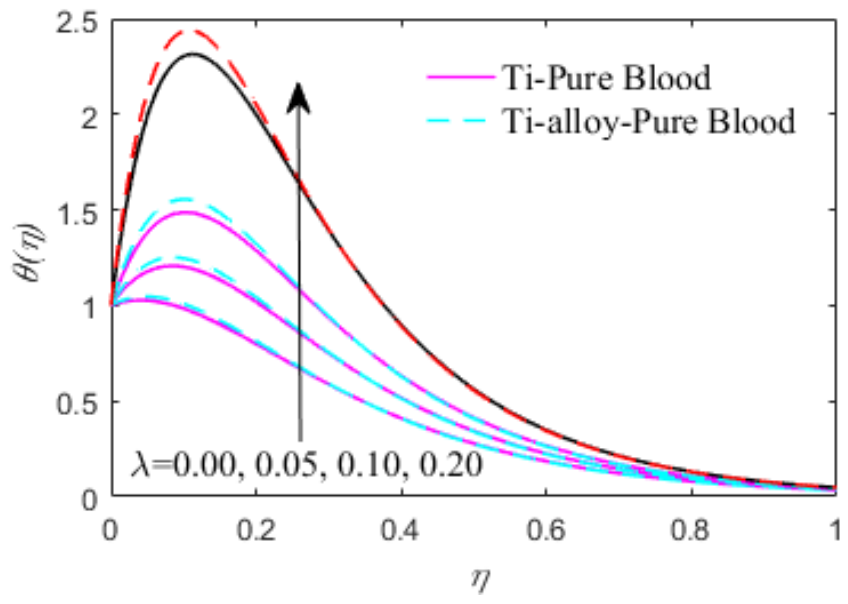

Fig. 12 Effect of $\lambda$ on temperature profile

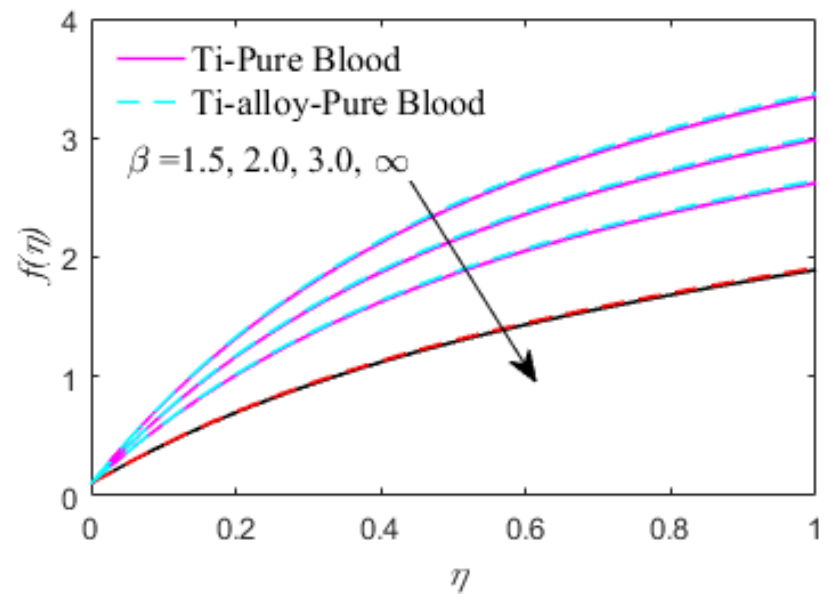

Fig. 13 Effect of $\beta$ on dimensionless stream function

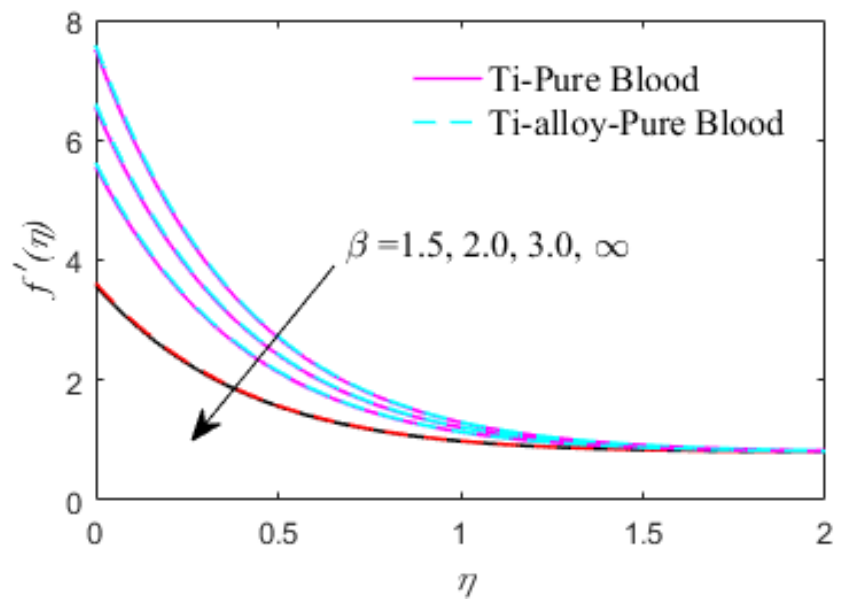

Fig. 14 Effect of $\beta$ on velocity profile 


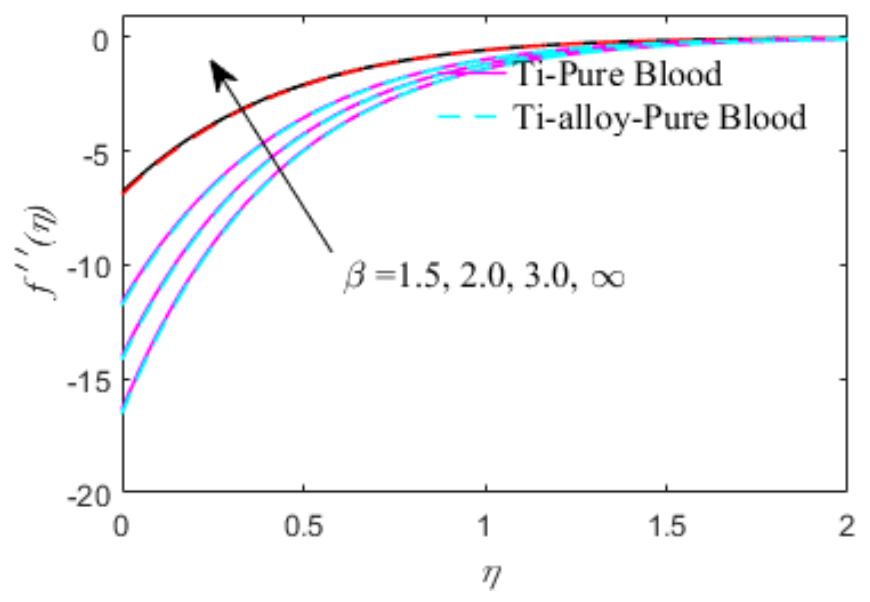

Fig. 15 Effect of $\beta$ on shear stress

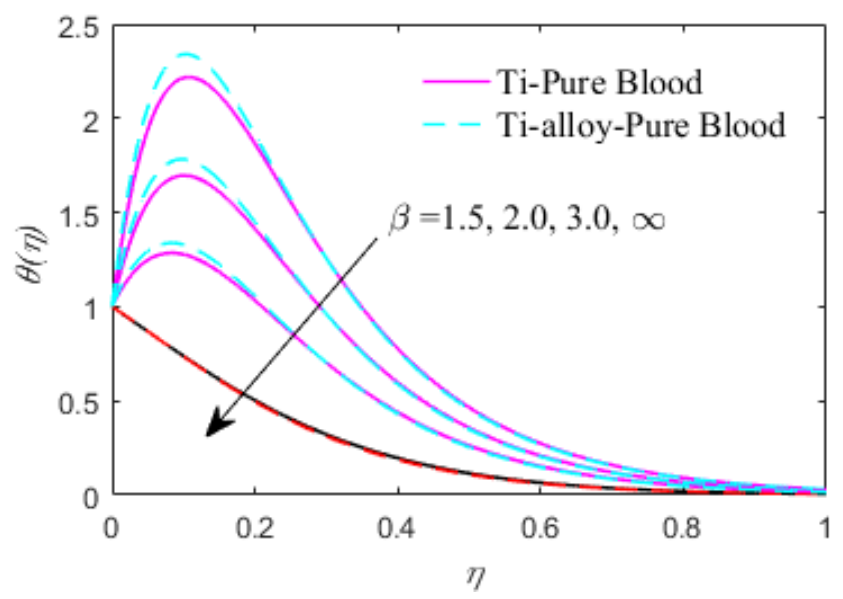

Fig. 16 Effect of $\beta$ on temperature profile

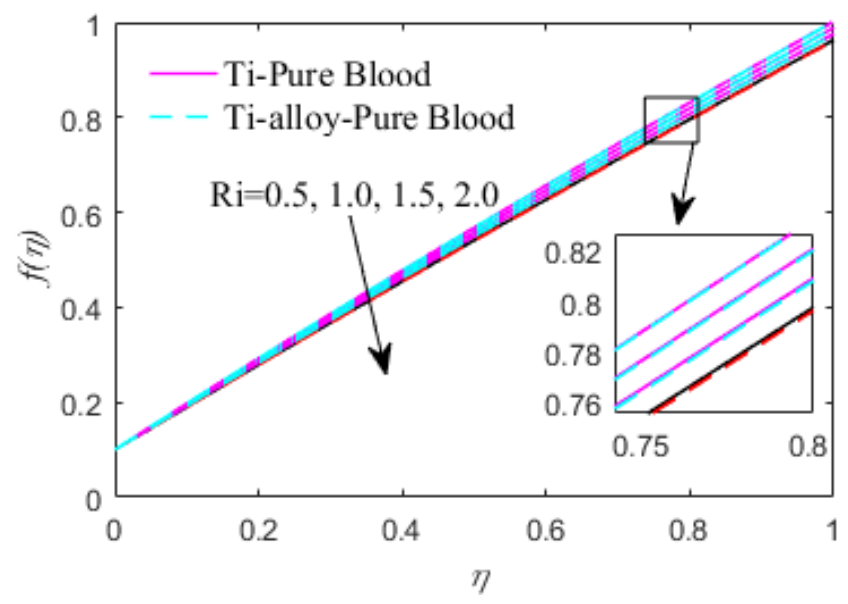

Fig. 17 Effect of $R i$ on dimensionless stream function

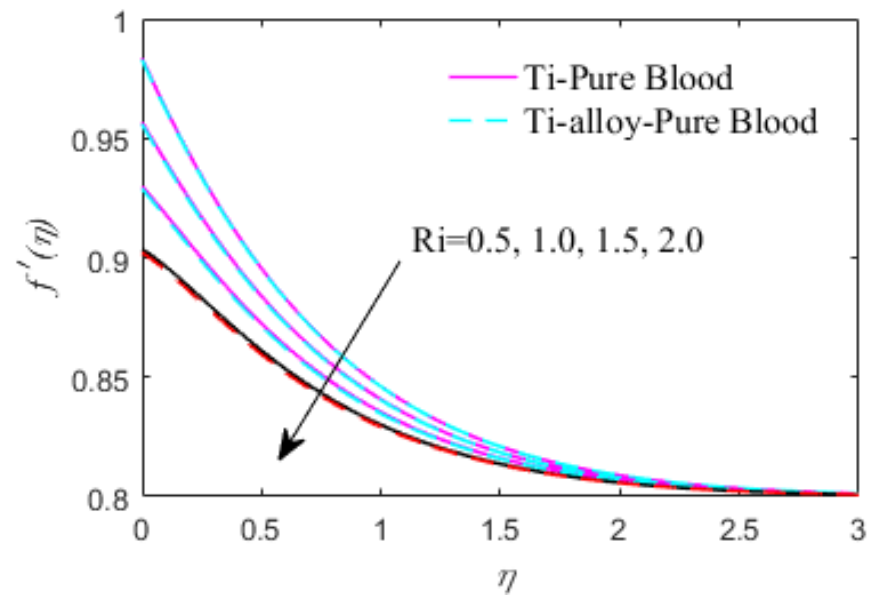

Fig. 18 Effect of $R i$ on velocity profile

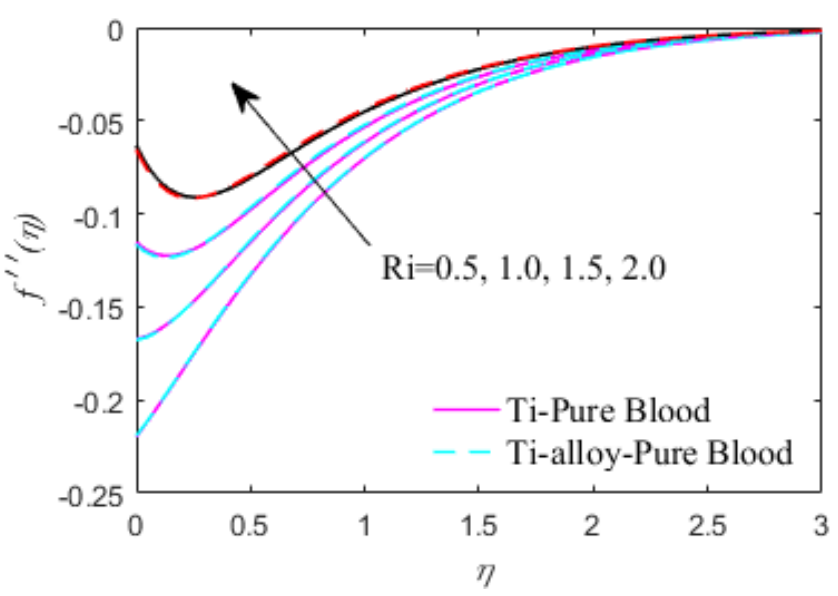

Fig. 19 Effect of $R i$ on shear stress

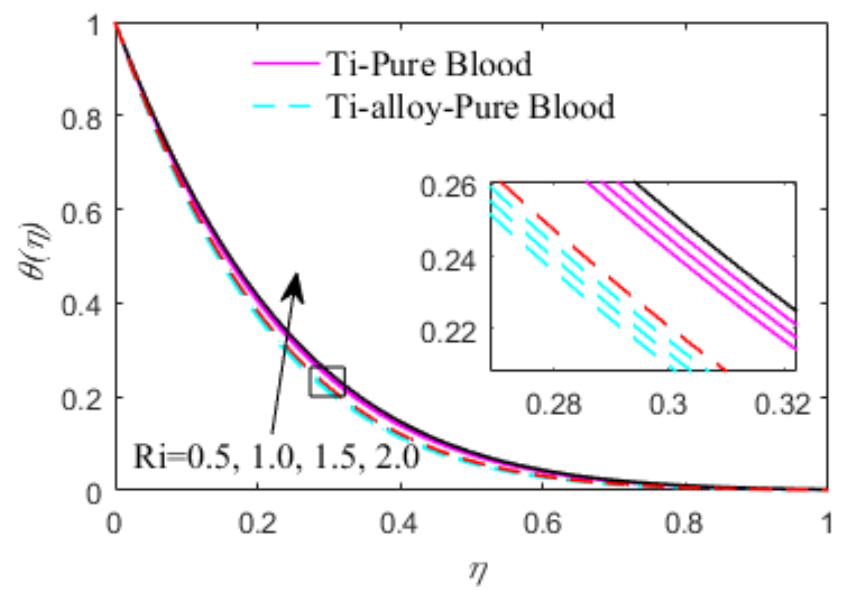

Fig. 20 Effect of $R i$ on temperature profile 


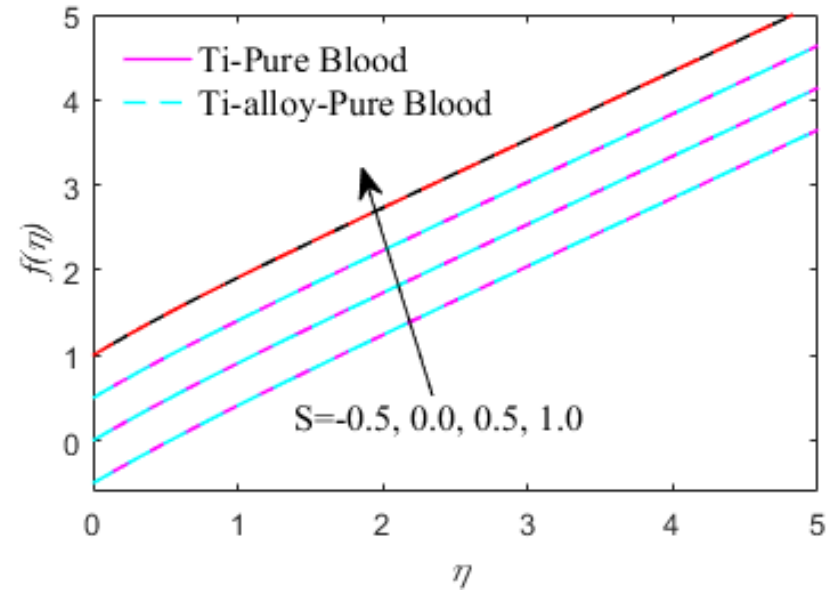

Fig. 21 Effect of $S$ on dimensionless stream function

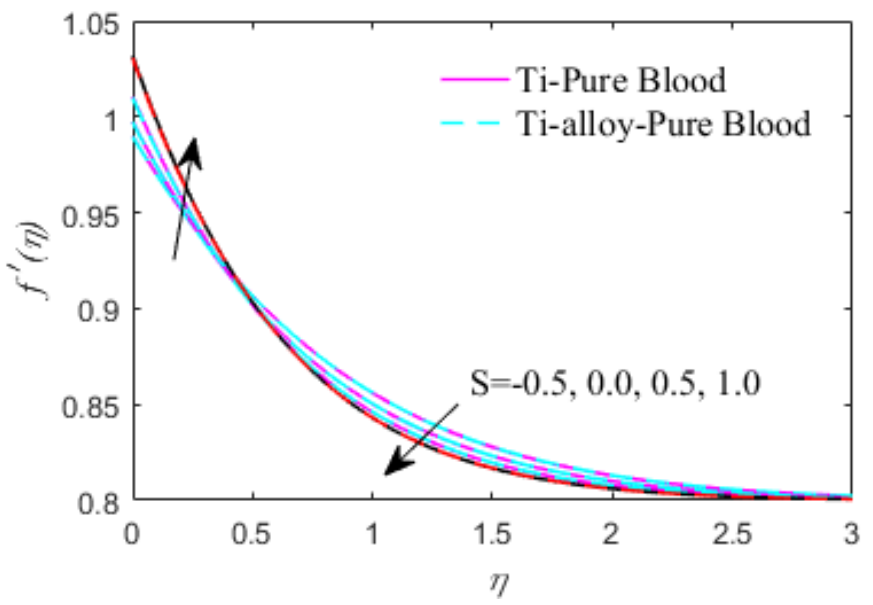

Fig. 22 Effect of $S$ on velocity profile

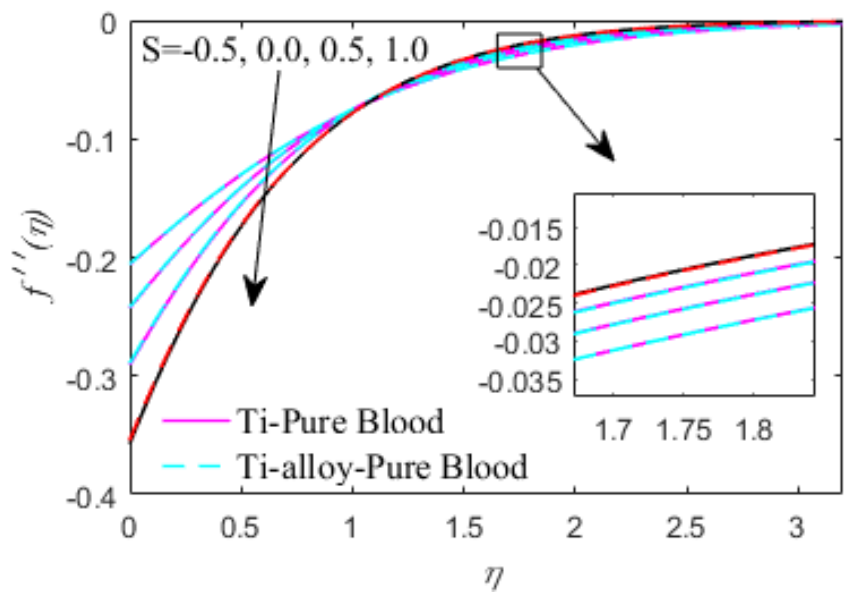

Fig. 23 Effect of $S$ on shear stress

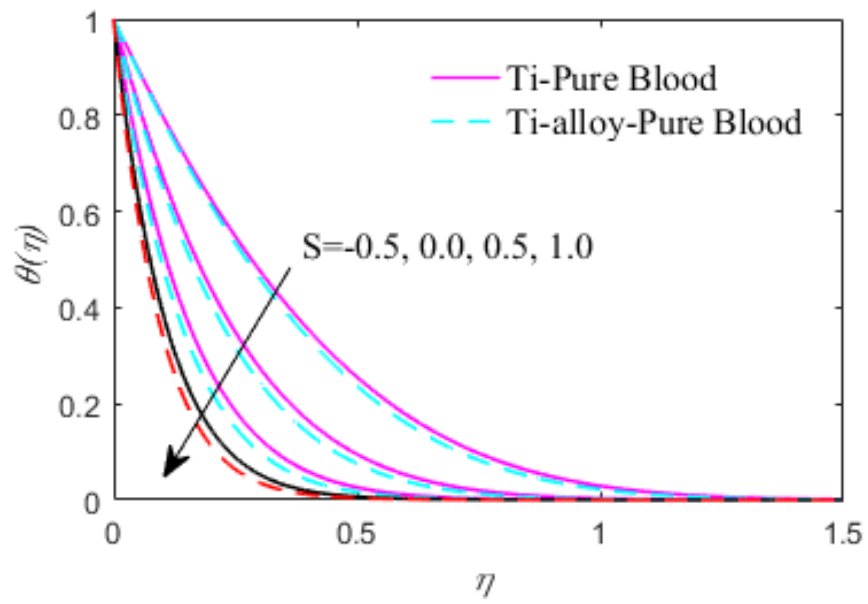

Fig. 24 Effect of $S$ on temperature profile

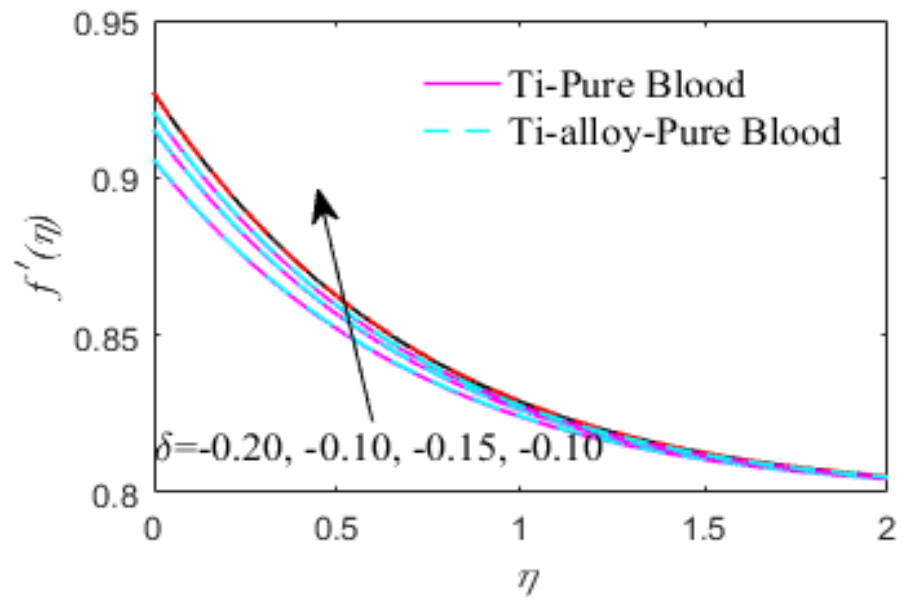

Fig. 25 Effect of $\delta$ on velocity profile

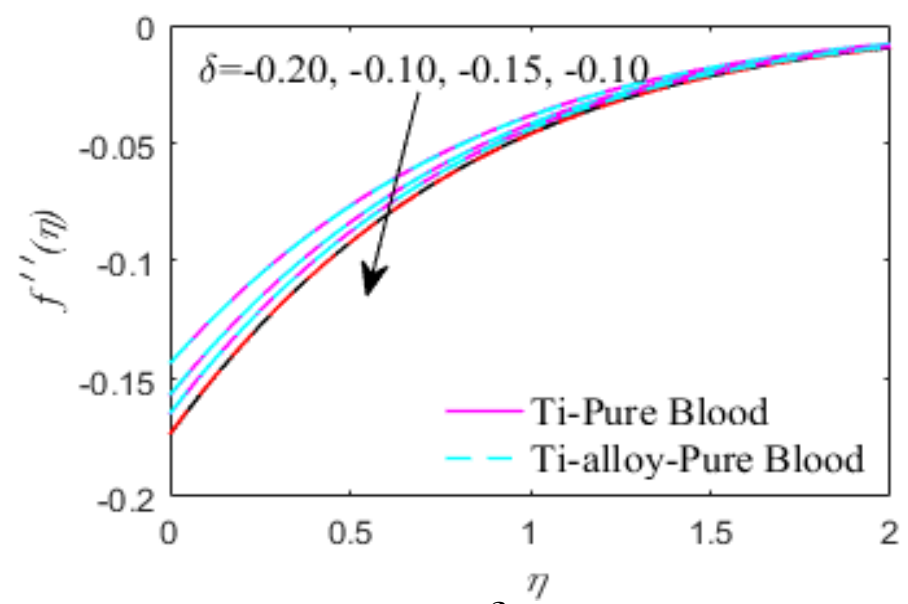

Fig. 26 Effect of $\delta$ on shear stress 


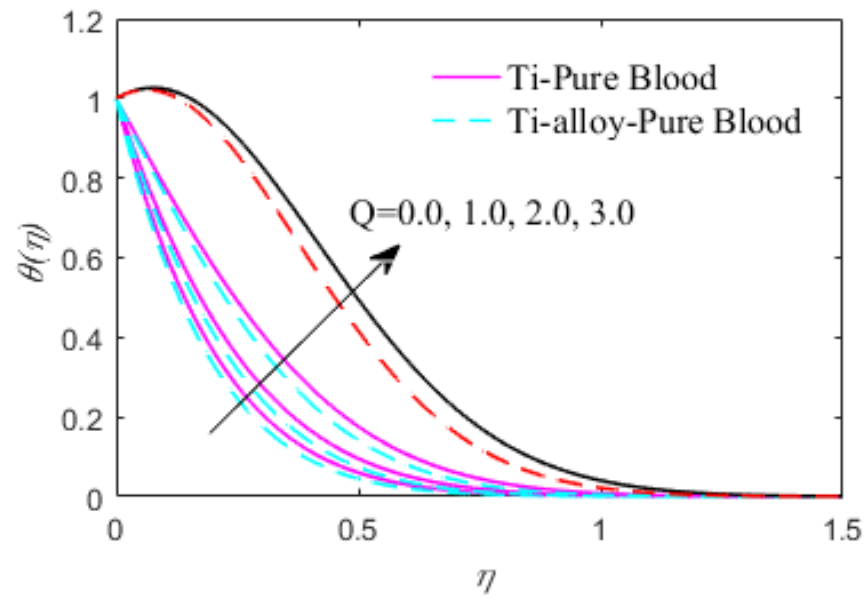

Fig. 27 Effect of $Q$ on temperature profile

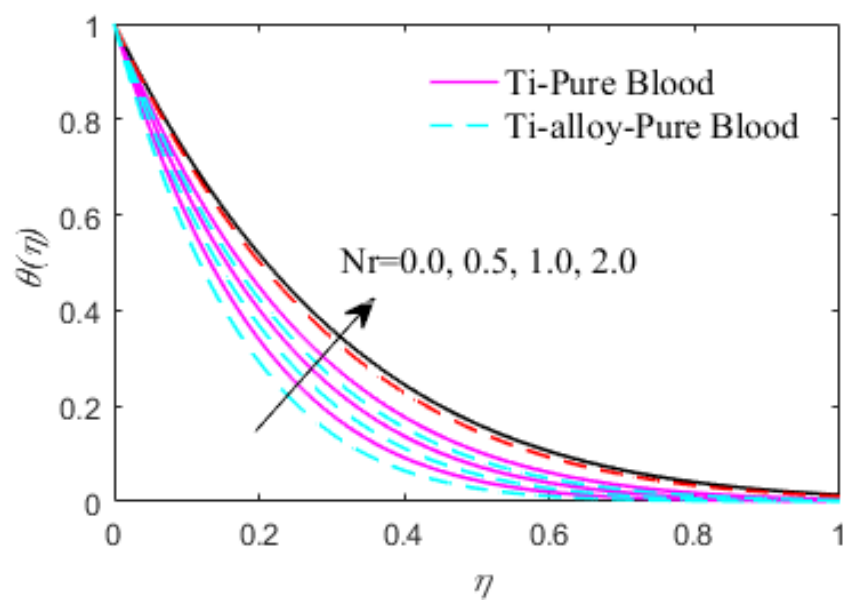

Fig. 28 Effect of $N r$ on temperature profile

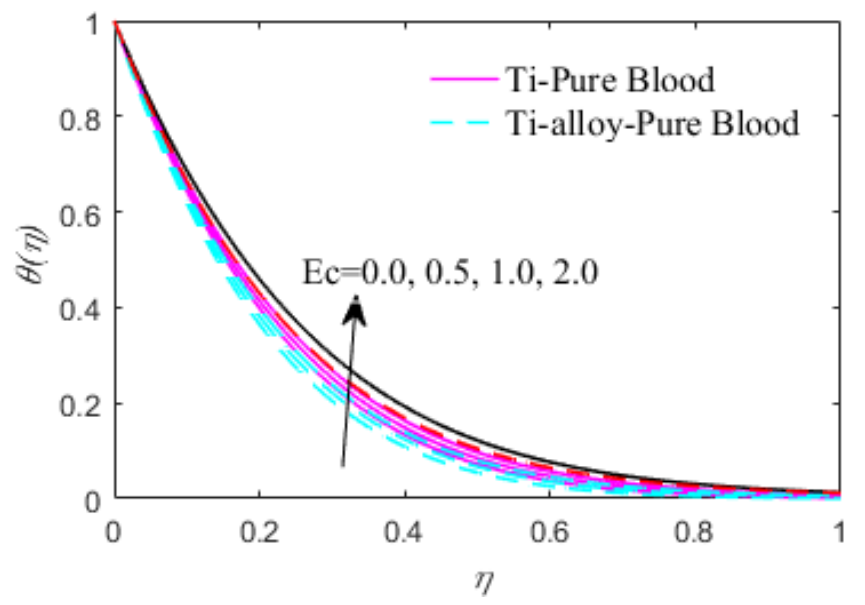

Fig. 29 Effect of $E c$ on temperature profile

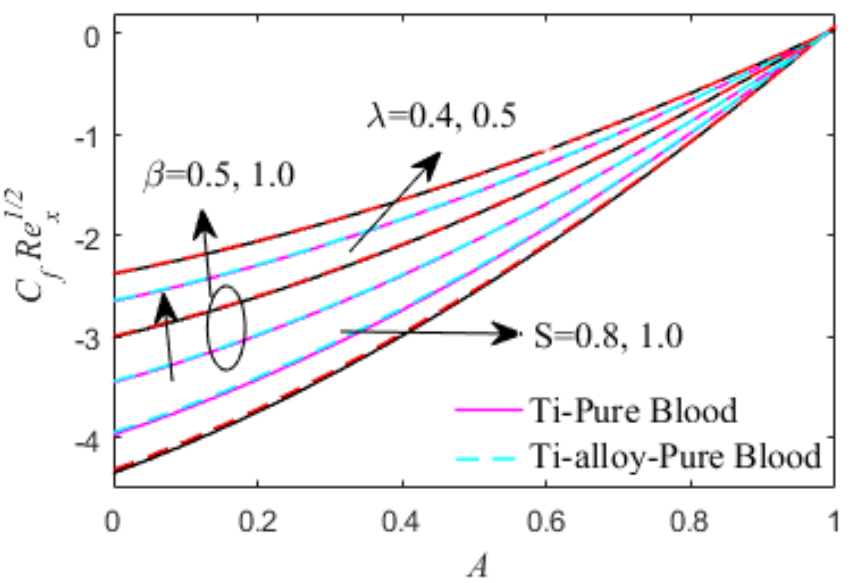

Fig. 30 The variation of skin friction coefficient against first order velocity slip, Casson fluid, suction, ratio parameters.

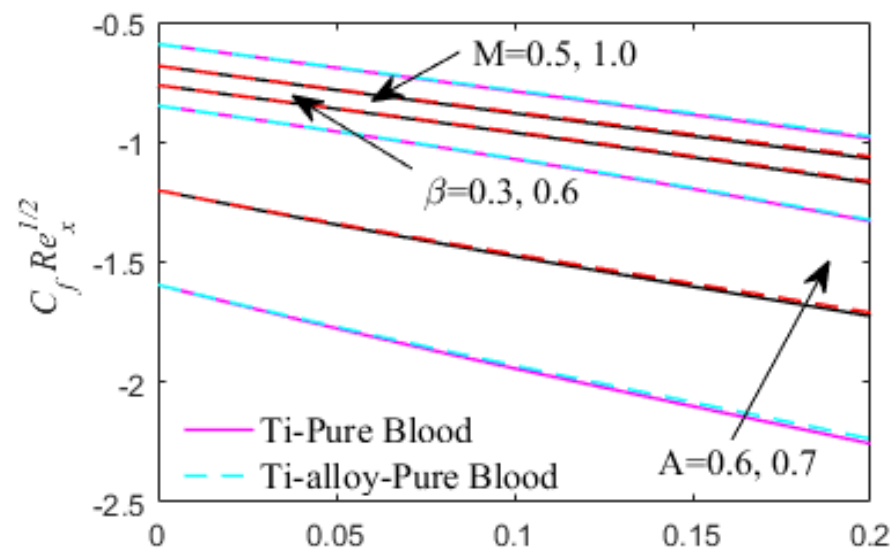

Fig. 31 The variation of skin friction coefficient against magnetic, Casson fluid, volume fraction and ratio parameters.

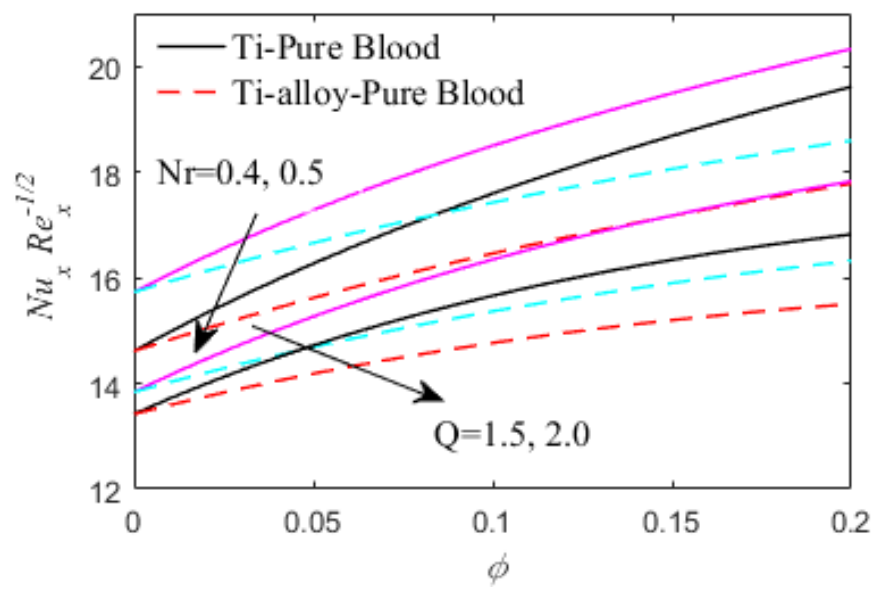

Fig. 32 The variation of Nusselt number against heat source, volume fraction and radiation conduction parameter 
For the accuracy and validity, we compared the present numerical values corresponding to the $-f^{\prime \prime}(\eta)$ with that of Hamad and ferdows (2012), Mahapatra and gupta (2002) (Table 2). Moreover, Table 3 presents the numerical values corresponding to $m$ compared with the previously published numerical results of Cortell (2007).

Table 1 numerical values of thermo physical properties of base fluid and nanoparticles.

\begin{tabular}{llll}
\hline $\begin{array}{l}\text { Physical } \\
\text { properties }\end{array}$ & Base fluids & \multicolumn{2}{l}{ Nanoparticles } \\
\cline { 2 - 4 } & Pure Blood & Ti & Ti-alloy \\
\hline$\rho\left(\mathrm{kg} / \mathrm{m}^{3}\right)$ & 1063 & 4510 & 4420 \\
$C_{p}(\mathrm{~J} / \mathrm{kg} \mathrm{K})$ & 3594 & 540 & 526.3 \\
$k(\mathrm{~W} / \mathrm{m} \mathrm{K})$ & 0.492 & 20.9 & 6.7 \\
$\beta \times 10^{-5}(1 / \mathrm{K})$ & 0.18 & 0.90 & 0.89 \\
\hline
\end{tabular}

Table 2 Comparison of $-f^{\prime \prime}(0)$ with Mahapatra and gupta (2002) and Hamad and ferdows (2012) for various values of $A$ when $p r=5.0, \beta=\infty, \delta=\lambda=N r=M=R i=Q=\phi=0$, and $\alpha=\pi / 2$.

\begin{tabular}{llllll}
\hline$A$ & $\begin{array}{l}\text { Mahapatra } \\
\text { and gupta } \\
\text { (2002) }\end{array}$ & $\begin{array}{l}\text { Present } \\
\text { Results }\end{array}$ & $m$ & $\begin{array}{l}\text { Hamad and } \\
\text { ferdows } \\
(2012) \\
-f^{\prime \prime}(0)\end{array}$ & $\begin{array}{l}\text { Present } \\
\text { Results }\end{array}$ \\
\hline 0.1 & 0.9694 & 0.969386 & 0.5 & 0.889544 & 0.889544 \\
0.2 & 0.9181 & 0.918107 & 1.0 & 1.000000 & 1.000000 \\
0.5 & 0.6673 & 0.667264 & 3.0 & 1.148593 & 1.148593 \\
\hline
\end{tabular}

Table 3 Comparison of $-\theta^{\prime}(0)$ with Cortell (2007) for various values of $m$ when $p r=5.0, \beta=\infty, \delta=\lambda=N r=M=S=R i=Q=\phi=0 \quad$ and $\alpha=\pi / 2$.

\begin{tabular}{lllll}
\hline$m$ & $-\theta^{\prime}(0)$ & & \multicolumn{2}{l}{$-\theta^{\prime}(0)$} \\
& $P r=1, E c=0$ & & \multicolumn{2}{l}{$\operatorname{Pr}=1, E c=0.1$} \\
\cline { 2 - 5 } & $\begin{array}{l}\text { Cortell } \\
(2007)\end{array}$ & $\begin{array}{l}\text { Present } \\
\text { Results }\end{array}$ & $\begin{array}{l}\text { Cortell } \\
(2007)\end{array}$ & $\begin{array}{l}\text { Present } \\
\text { Results }\end{array}$ \\
\hline 0.75 & 1.252672 & 1.252701 & 1.219985 & 1.219940 \\
1.5 & 1.439393 & 1.439375 & 1.405078 & 1.405184 \\
7.00 & 1.699298 & 1.699318 & 1.662506 & 1.662599
\end{tabular}

\section{CONCLUSION}

Recently, many investigators are attracted to study of the effects of heat and chemical reactions on the blood from the theoretical and experimental point of view because the quantitative prediction of blood flow rate and heat generation are of importance for the non-invasive measurement of blood glucose and for diagnosing blood circulation illness. The motivation behind the present examination is to inspect the significance of nanofluid over a stretching sheet with the first-order and second-order velocity slips using the $\mathrm{Ti}$ and $\mathrm{Ti}$-alloy nanoparticles on blood (as the base fluid).

- The velocity profiles are increased with increasing values of ratio parameter, first order velocity slip parameter, second order velocity slip parameter and suction/blowing parameter for both Ti-pure blood and Ti-alloy-pure blood cases.
- $\quad$ The velocity profiles are decrease with increasing the values of Richardson number, Casson fluid parameter and magnetic parameter for both cases.

- An increasing in the suction/blowing parameter the velocity increases at certain interval after that a slight decrease in velocity.

- The rate of heat transfer is higher in Ti-alloy-pure blood nanofluid when compared with the Ti-pure blood nanofluid due to the additives of alumina and vanadium in Ti-alloy.

- An increase in the Casson fluid parameter and ratio parameter leads to increasing the effect of local skin friction coefficient.

- Higher values of suction parameter result in the enhancement of local skin friction coefficient while it decreases for large values of ratio parameter.

- The local Nusselt number decrease with increase of radiation conduction parameter and the heat source parameter.

\section{REFERENCES}

Vajravelu, K., 2001, "Viscous Flow Over a Nonlinearly Stretching Sheet," Appl Math Comput, 124, 281-288. https://doi.org/10.1016/S0096-3003(00)00062-X

Elbashbeshy, E.M.A., 1998, "Heat Transfer over a Stretching Surface with Variable Surface Heat Flux," J Phys D: Appl Phys. 31, 19511954.

Thirupathi Thumma, Anwar Beg, O. and Kadir A., 2017, "Numerical Study of Heat Source/Sink Effects on Dissipative Magnetic Nanofluid Flow From a Non-Linear Inclined Stretching/Shrinking Sheet," Journal of Molecular Liquids, 232, 159-173.

https://doi.org/10.1016/j.molliq.2017.02.032

Hamad, M.A.A. and Ferdows, M., 2012, "Similarity Solutions to Viscous Flow and Heat Transfer of Nanofluid over Non-Linearly Stretching sheet," Appl. Math. Mech. 33(7), 923-930. https://doi.org/10.1007/s10483-012-1595-7

Bhatti, M.M., Ali Abbas, M. and Rashidi, M.M., 2018, "A robust numerical method for solving stagnation point flow over a permeable shrinking sheet under the influence of MHD," Applied Mathematics and Computation, 316, 381-389.

https://doi.org/10.1016/j.amc.2017.08.032

Idrees, M., Sajid Rehman, Rehan Ali Shah, Ullah, M., and Tariq Abbas, 2018, "A similarity solution of time dependent MHD liquid film flow over stretching sheet with variable physical properties," Results in Physics, 8, 194-205.

https://doi.org/10.1016/j.rinp.2017.12.009

Seth, G. S., Mishra, M. K. and Tripathi R., 2018 "MHD free convective heat transfer in a Walter's liquid-B fluid past a convectively heated stretching sheet with partial wall slip," Journal of the Brazilian Society of Mechanical Sciences and Engineering, 40:103, 1-11. https://doi.org/10.1007/s40430-018-1028-5

Mahapatra, T.R and Gupta, A., 2002, "Heat Transfer in StagnationPoint Flow towards a Stretching Sheet," Heat Mass Transfer, 38 517521. https://doi.org/10.1007/s002310100215

Ali, M.E., 1994, "Heat Transfer Characteristics of a Continuous Stretching Surface," Heat Mass Transfer, 29, 227-234. https://doi.org/10.1007/BF01539754

Bala Anki Reddy, P. and Vijaya Sekhar, D., 2013, "Effects of Radiation on MHD Mixed Convection Flow of a Micropolar Fluid over a Heated Stretching Surface with Heat Generation/Absorption," International journal of Engineering Research and Applications, 3, 572-581.

Cortell, R., 2007, "Viscous Flow and Heat Transfer Over a Nonlinearly Stretching Sheet," Appl. Math Comput. 184, 864-873. 


\section{https://doi.org/10.1016/j.amc.2006.06.077}

Srinivas, S., Reddy, P.B.A. and Prasad, B.S.R.V., 2014, "Effects of Chemical Reaction and Thermal Radiation on MHD Flow Over an Inclined Permeable Stretching Surface with Nonuniform Heat Source/Sink: an Application to the Dynamics of Blood Flow," Journal of Mechanics in Medicine and Biology, 14, 1450067-1-24. https://doi.org/10.1142/S0219519414500675

Rana, P. and Bhargava, R., 2017, "Flow and Heat Transfer of a Nanofluid over a Nonlinearly Stretching Sheet: A numerical study," Comm. Nonlinear. Sci. Num. Simul. 17, 212-226.

https://doi.org/10.1016/j.cnsns.2011.05.009

Pop, S., Grosan, T. and. Pop, I. 2004, "Radiation Effects on the Flow Near the Stagnation Point of a Stretching Sheet," Technische Mechanik 25, 100-106.

https://www.researchgate.net/publication/273059667

Sharma, P. and Singh, G. 2009, "Effects of Variable Thermal Conductivity and Heat Source/Sink on MHD Flow Near a Stagnation Point on a Linearly Stretching Sheet," J. Appl. Fluid Mech. 2, 13-21.

Thirupathi Thumma, Anwar Beg O. and Kadir, A., 2017, "Numerical Study of Heat Source/Sink Effects on Dissipative Magnetic Nanofluid Flow from a Non-Linear Inclined Stretching/Shrinking Sheet," Journal of Molecular Liquids, 232, 159-173.

https://doi.org/10.1016/j.molliq.2017.02.032

Charm, S., Paltiel, B. and Kurland, G.S., 1968, "Heat Transfer Coefficients in Blood Flow," Biorheology 5, 133-145.

Victor, S.A. and Shah, V.L., 1975, "Heat Transfer to Blood Flowing in a Tube," Biorheology, 12, 361-368.

Victor, S.A. and Shah, V.L., 1976, "Steady State Heat Transfer to Blood Flowing in the Entrance Region of a Tube," Int J Heat Mass Transfer, 19, 777-783.

https://doi.org/10.1016/0017-9310(76)90131-9

Li, J. and Huang, H., 2010, "Effect of Magnetic Field on Blood Flow and Heat Transfer Through a Stenosed Artery," 3rd Int. Conf. Biomed Eng Infor, 2028-2032.

https://doi.org/10.1109/BMEI.2010.5639654

Gireesha, B.J., Mahanthesh, B. and Rashidi, M.M., 2015, "MHD Boundary Layer Heat and Mass Transfer of a Chemically Reacting Casson Fluid Over a Permeable Stretching Surface with Non-Uniform Heat Source/Sink," International Journal of Industrial Mathematics. 7, 247-260.

Dash, R.K., Mehta, K.N. and Jayaraman, G., 1996, "Casson Fluid Flow in a Pipe Filled With a Homogeneous Porous Medium," Int. J. Eng. Sci. 34, 1145-56.

https://doi.org/10.1016/0020-7225(96)00012-2

Thirupathi Thumma, and Mishra, S. R., 2018, "Effect of Viscous Dissipation and Joule Heating on MHD Jeffery Nanofluid Flow With and Without Multi Slip Boundary Conditions," J. nanofluids, 7(3), 516526. https://doi.org/10.1166/jon.2018.1469

Bala Anki Reddy, P., 2016, "Magnetohydrodynamic Flow of a Casson Fluid Over an Exponentially Inclined Permeable Stretching Surface with Thermal Radiation and Chemical Reaction," Ain Shams Engineering Journal, 7, 593-602. https://doi.org/10.1016/j.asej.2015.12.010

Nadeem, S., Rizwan Ul Haq, Noreen Sher Akbar, and Khan, Z.H., 2013, "MHD Three-Dimensional Casson Fluid Flow Past a Porous Linearly Stretching Sheet," Alexandria Engineering Journal, 52, 577582.

https://doi.org/10.1016/j.aej.2013.08.005

Mahanta, G. and Shaw, S., 2015, "3D Casson Fluid Flow Past a Porous Linearly Stretching Sheet with Convective Boundary Condition," Alexandria Engineering Journal, 54, 653-659. https://doi.org/10.1016/j.aej.2015.04.014

Mustafa, M., Hayat, T., Pop, I. and Aziz, A., 2011, "Unsteady Boundary Layer Flow of a Casson Fluid Due to an Impulsively Started Moving Flat Plate," Heat Transfer Asian Research, 40, 563-576. https://doi.org/10.1002/htj.20358

Nadeem, S., Haq, R. U. and Lee, C., 2012, "MHD Flow of a Casson Fluid over an Exponentially Shrinking Sheet," Scientia Iranica, 19, 1550-1553. https://doi.org/10.1016/j.scient.2012.10.021

Choi SUS, and Eastman, J. A., 1995, "Enhancing Thermal Conductivity of Fluids With Nanoparticles, The Proceedings of the ASME International Mechanical Engineering Congress and Exposition," San Francisco, 66, 99-105, USA, ASME, FED. 231/MD.

Mustafa, M., Hayat, T., Pop, I., Asghar, S. and Obadiat, S., 2011, "Stagnation-Point Flow of a Nanofluid Towards a Stretching Sheet," Int. J. Heat and Mass Transf. 54, 5588-5594.

https://doi.org/10.1016/j.ijheatmasstransfer.2011.07.021

Nield, D.A. and Kuznetsov, A.V., 2009, "The Cheng-Minkowycz Problem for Natural Convective Boundary-Layer Flow in a Porous Medium Saturated by a Nanofluid," Int. J. Heat and Mass Transf. 52, 5792-5795.

https://doi.org/10.1016/j.ijheatmasstransfer.2009.07.024

Hayat, T., Farooq, M. and Alsaedi, A., 2016, "HomogeneousHeterogeneous Reactions in the Stagnation Point Flow of Carbon Nanotubes with Newtonian Heating," AIP Advances, 6, 027130. http://dx.doi.org/10.1063/1.4908602

Siva Reddy Sheri, and Thirupathi Thumma, 2016, "Heat and Mass Transfer Effects on Natural Convection Flow in the Presence of Volume Fraction for Copper-Water Nanofluid," Journal of nanofluids, 5 (2), 220-230. https://doi.org/10.1166/jon.2016.1214 